\title{
REFLECTIR CONTRADITORIAMENTE AS CONTRADIÇÕES
}

\author{
Carlos Morujão ${ }^{1}$
}

(UCP - Centro de Estudos de Filosofia)

\section{Introdução}

A expressão que está colocada no título deste breve ensaio é de Vasco de Magalhães-Vilhena e insere-se num contexto que convém desde já esclarecer: ela pertence ao livro publicado em 1965 intitulado António Sérgio, o Idealismo Crítico e a Crise da Ideologia Burguesa, no qual o autor procura fazer uma avaliação da obra ensaística de Sérgio e do modo como ela se insere - reflectindo-a - na realidade portuguesa sua contemporânea. Por esta razão, numa primeira versão do meu título, que a organização do colóquio onde o texto foi lido deixou cair, continuava dizendo que me propunha interpretar uma frase sobre Sérgio. Mas o facto de essa parte do meu título ter caído talvez tenha sido uma circunstância feliz: permitiu-me, neste ensaio, falar mais livremente de Magalhães-Vilhena e de alguns aspectos do seu pensamento filosófico, embora mantendo o livro de 1965 no horizonte da minha interpretação².

Antes propriamente de iniciar tenho de chamar a atenção para o verbo "reflectir", que há pouco empreguei, pois "reflexo" e "reflexão" são dois termos que Magalhães-Vilhena emprega quase sempre como se fossem sinónimos. Julgo que essa sinonímia é indefensável em vários dos contex-

1 cmorujao@fch.lisboa.ucp.pt

2 Remeterei, ao longo deste ensaio, para a reimpressão de 1975 (Vasco de Magalhães-Vilhena, António Sérgio, o Idealismo Crítico e a Crise da Ideologia Burguesa, Lisboa: Editorial Cosmos, 1975), que conserva a paginação da edição original.

Philosophica, 49, Lisboa, 2017, pp. 27-38. 
tos em que o autor afirma que ela existe. Como em muitas passagens do seu livro Magalhães-Vilhena me parece empregar indiferenciadamente os dois termos, segui-lo-ei muitas vezes nesse emprego, mesmo quando assinalo aqueles contextos em que a sinonímia não me parece admissível. Todavia, chamo também a atenção para o facto de que o meu primeiro interesse não é saber se há ou não teses filosoficamente menos defensáveis neste escrito de Magalhães-Vilhena. Qualquer que venha a ser a resposta, o fundamental, para mim, está noutro lado. A doutrina do reflexo - subjacente ao emprego daquele "reflectir" que acabei de referir -, exposta em partes significativas desta obra e pressuposta em toda ela, releva de uma certa concepção de homem e conduz a uma certa concepção de experiência. E são estas concepções de Magalhães-Vilhena que me interessa interrogar, não tanto para ver se conseguem dar conta daquilo a que se propõem, mas sim, sobretudo, porque aquilo que se propõem a mim também me interessa pensar.

Ora bem: aquela noção de "reflexo contraditório" de uma realidade contraditória parece-me necessitar de algum esclarecimento. Defende Magalhães-Vilhena que há um reflexo da prática social material na prática ideal, sendo esta última o processo de pensar aquela. Com efeito, prossegue Magalhães-Vilhena, existe uma acção-recíproca entre a obra e a realidade social, falando-se de reflexo para evidenciar a relação de dependência da primeira - ou seja da obra - em relação à segunda. Postas as coisas nestes termos, creio que todos poderemos aceitar a teoria do reflexo que nos é proposta. Mas julgo que a noção de "reflexo contraditório" fica ainda por explicar. E se admitirmos que a prática social material (utilizando a expressão de Magalhães-Vilhena) se reflecte em toda a prática ideal, tal deverá valer também para esse tipo de prática ideal que é a obra do próprio Magalhães-Vilhena. Será ela também um reflexo contraditório? Seríamos tentados a responder que sim, para manter a coerência da teoria; mas provavelmente a resposta será não, uma vez que - avanço a título de hipótese - apenas é contraditório o reflexo que não reconhece a natureza das contradições da realidade que reflecte. (Este parece ter sido o caso de Sérgio, de acordo com Magalhães-Vilhena ${ }^{3}$.)

Convém, todavia, delimitar o âmbito das considerações seguintes sobre o reflexo, porque me parece que Magalhães-Vilhena recorre a este

\footnotetext{
Que o reflexo ideal de uma certa prática material possa ser, por vezes, contraditório e que, por conseguinte, seja ele próprio, enquanto reflexo, mediado culturalmente, parece ser também algo que se pode admitir sem problema. O problema começa noutro lado, a saber, quando perguntamos por que razão esse reflexo assume uma forma em certos autores (Sérgio, por exemplo) e forma diferente noutros autores (Magalhães-Vilhena, para escolhermos outro exemplo). Será a origem social de um e do outro - diferente nos dois casos, como sabemos - a explicação para este facto?
} 
conceito em quatro situações distintas. Por um lado, sobretudo no capítulo $1 .{ }^{\circ}$, no contexto de uma teoria da percepção em sentido lato, que transparece em frases como esta:

As "imagens" da realidade (...) não se identificam com a realidade de que são reflexo. Por muito que uma imagem reflicta a realidade material, não coincide de maneira total e completa com ela. Os fenómenos perceptivos, a representação sensível, não são a realidade mesma, mas o seu reflexo 4 .

Por outro lado, no contexto de uma teoria da percepção a que eu chamaria "culturalmente informada", como transparece da afirmação seguinte: "pela actividade própria do sujeito, marcada sempre por um conteúdo socialmente elaborado em determinadas condições históricas (...) se há-de compreender e explicar a relação entre a sensoriedade e o pensar e o real objectivo." ${ }^{5}$ Por outro ainda, sempre que se refere à percepção que se realiza em contextos mais específicos, orientada por interesses de conhecimento que pertencem ao âmbito das ciências da natureza; assim, é dito que "as ideias e teorias têm a prática (...) por base e objectivo; elas elaboram-se, enriquecem-se, desenvolvem-se e comprovam-se na experiência prática, que é tanto o operar do químico e do físico no laboratório, como o do agrobiologista ou do geólogo no terreno [...]."

Por fim, "reflexo" aparece ainda num contexto como aquele em que aparece a frase que pus no título deste ensaio. Percepção designa agora o contacto com a realidade social, com o objectivo de a conhecer e agir em vista da sua transformação. Neste mesmo contexto enquadra-se a afirmação de que os quadros sociais que subjazem ao "ambiente mental" em que se desenvolve a actividade intelectual de Sérgio têm - em resultado da divisão da sociedade em classes - um carácter contraditório e antagónico, sendo a percepção deles por Sérgio um reflexo desse seu carácter?

\section{A doutrina do reflexo}

As últimas afirmações que reproduzi situam-se já no Capítulo $4 .^{\circ}$ da obra de Magalhães-Vilhena sobre Sérgio, mas para as compreender cabal-

\footnotetext{
${ }^{4}$ Vasco de Magalhães-Vilhena, António Sérgio, o Idealismo Crítico e a Crise da Ideologia Burguesa, p. 52.

5 Ibidem, p. 60.

6 Ibidem, p. 61.

7 Ibidem, p. 130.
} 
mente há que lê-las à luz do Capítulo $1^{\circ}$, ao qual pertencem as primeiras três citações e onde se contrapõe, ao idealismo filosófico de Sérgio, um materialismo gnosiológico apoiado na doutrina do reflexo. Não poderei abordar o conjunto de problemas tratados neste Capítulo $1 .^{\circ}$, em particular a relação de Sérgio com a filosofia neo-kantiana, assunto a que, aliás, dediquei já, em tempos, algumas páginas. Irei centrar-me na questão da polémica, para lhe chamar assim, entre idealismo e materialismo e a crítica feita à gnosiologia de Sérgio do ponto de vista da doutrina do reflexo. É provável que o que Magalhães-Vilhena entende por idealismo não seja exactamente o que eu entendo, assim como a referida polémica não tem para mim a importância que teve para Magalhães-Vilhena e que terá ainda, suponho, para quem se situa em idênticas paragens filosóficas. Parece-me, aliás, problemático que se subsuma sob um idêntico conceito de "matéria", tanto o chamado real exterior à consciência, como o ser social, ou seja, o resultado objectivado dos processos de trabalho que asseguram a reprodução da espécie humana, para se estabelecer, dessa forma, as bases de um materialismo filosófico. Reconheço, todavia, que é esta identificação - que remonta, pelo menos, ao Anti-Dühring de Friedrich Engels - que se encontra na base do que se considera o materialismo marxista ${ }^{8}$. Recorro a uma breve citação para exemplificar a posição de Magalhães-Vilhena sobre este assunto:

A categoria filosófica de matéria não só admite a existência de um fundamento objectivo dos fenómenos da nossa consciência (...) como reconhece a existência real e objectiva do ser natural (a matéria), independente da nossa consciência e da experiência da humanidade e de toda a classe de forças suprassensíveis (...) como reconhece outrossim a existência do ser social independente da consciência social dos homens - o que implica a inclusão da base material da sociedade humana no conceito de matéria $[\ldots]^{9}$.

Deixarei de lado, até porque o assunto não o exige e o tempo é escasso, algumas pistas que Magalhães-Vilhena, talvez involuntariamente, abre para uma possível abordagem - ou para uma crítica - da teoria do reflexo. Por exemplo, aquela que o conduz, na esteira de Sérgio, a perguntar: de que

8 Friedrich Engels, Herrn Eugen Dührings Umwälzung der Wissenschaft, in Karl Marx / Friedrich Engels, Werke, Berlin, Dietz Verlag, 1968, Band 20, p. 20: „Wenn wir die Natur oder die Menschengeschichte oder unsre eigne geistige Tätigkeit der denkenden Betrachtung entwerfen, so bietet sich uns zunächst dar das Bild einer unendlichen Verschlingung von Zusammenhängen und Wechselwirkungen, in der nichts bleibt, was, wo und wie es war, sondern alles sich bewegt, sich verändert, wird und vergeht.“

9 Vasco de Magalhães-Vilhena, António Sérgio, o Idealismo Crítico e a Crise da Ideologia Burguesa, pp. 43-44. 
é que a $\sqrt{ }-1$ será o reflexo? Julgo que enriqueceria a nossa compreensão do que Magalhães-Vilhena entende por reflexo se, na base dessa mesma doutrina do reflexo, nos propusesse uma explicação para a origem dos números imaginários. Ou proporá, eventualmente, só que, então, fui eu que não entendi tal explicação. Todavia, creio que não chega, de facto, a propor. Veja-se, por exemplo, a longuíssima nota 15, que começa na p. 26 e termina apenas no final da p. 31, em que Magalhães-Vilhena distingue a sua concepção de reflexo daquela que seria partilhada por "materialistas dogmáticos", para os quais a reflexão das coisas no cérebro dos homens se assemelha ao reflexo dos objectos na superfície de um espelho. Há, na sua concepção de reflexo, apesar da distinção que efectua, algo que o impede de abordar de facto a questão de há pouco. Para o explicar terei recorrer, de novo, a uma breve citação:

O pensamento teórico (abstracto) correcto, justo, ao elevar-se do concreto ao abstracto, acerca-se ainda mais da verdade, com maior profundidade e exactidão, pois reflecte a realidade objectiva não já na sua aparência sensível, mas nas suas relações internas, na sua estrutura; apreende, reproduz os nexos efectivos, sujeitos a leis, entre os fenómenos naturais e sociais ${ }^{10}$.

A realidade material objectiva, de acordo com este texto, parece compreender dois níveis: o da aparência sensível e o das relações internas, ou da estrutura; da mesma forma, parece que o conhecimento comportará também dois níveis, o da experiência sensível e o do pensamento abstracto, que reproduz os nexos efectivos entre os fenómenos, sejam naturais sejam sociais. Magalhães-Vilhena parece considerar que a distinção entre a aparência sensível e a estrutura inteligível captada pelo pensamento abstracto (que a traduz sob a forma de juízos, conceitos ou categorias) é uma distinção natural e evidente. Em qualquer dos casos, tratando-se da aparência sensível ou da estrutura inteligível, o problema consistiria em determinar como se processa a transposição e tradução delas no cérebro humano. Admito que esta transposição ou tradução - Magalhães-Vilhena recorre a dois termos de Marx: Umsetzung e Übersetzung ${ }^{11}$ - não se possa explicar pela noção de reflexo usada pelos tais materialistas dogmáticos. Mas o mais importante é que esta noção de abstração - corolário da suposição que existem processos materiais que são reproduzidos (abgebildet) no cérebro humano - precisaria ela própria de ser interrogada.

10 Ibidem, p. 57.

11 Karl Marx, Das Kapital, in Karl Marx / Friedrich Engels, Werke, ed. cit., Band 23, p. 27: „Bei mir ist (...) das Ideelle nichts andres als das im Menschenkopf umgesetzte und übersetzte Materielle.“ Cf. Vasco Magalhães-Vilhena, António Sérgio, o Idealismo 
A distinção entre um conhecimento sensível, concreto, e um conhecimento teórico resultante da operação de abstracção, traduz um certo estado das investigações psicofisiológicas sobre a natureza das operações mentais. É certo que Magalhães-Vilhena defende ${ }^{12}$ que existe uma actividade generalizadora elementar que opera já no momento do conhecimento sensorial, sem que a distinção entre uma psicologia sensualista - ocupada em relacionar as alterações fisiológicas com a intensidade das sensações - e uma psicologia das funções superiores do cérebro chegue a ser posta em causa. Com efeito, aquela primeira actividade generalizadora consiste apenas numa comparação entre sensações, efectuada graças à participação da actividade sintetizadora da secção superior do cérebro, ao passo que esta última actividade se encarrega de estabelecer nexos mais permanentes do que aqueles que resultam da generalização elementar efectuada pelo conhecimento sensível. Provavelmente com receio de cair numa qualquer variedade de idealismo, Magalhães-Vilhena não reconhece que o conhecimento sensorial é, em primeiro lugar, um conhecimento de si enquanto possibilidade de ser afectado; ou seja, reconhece apenas uma forma de espontaneidade, aquela que poderíamos dizer que é própria do "Eu penso" - no sentido kantiano da expressão - e não do "eu posso" - no sentido que Husserl dá a esta expressão -, a saber, a espontaneidade receptiva que caracteriza o corpo somático e é a condição de possibilidade da afecção ${ }^{13}$.

\section{A reflexologia de Pavlov}

Passarei, agora, a uma análise mais pormenorizada da doutrina pavloviana de reflexo, que Magalhães-Vilhena, em meu entender injustificadamente, quer relacionar com a noção hegeliana de reflexão, na Segunda Parte da Ciência da Lógica, de Hegel. Um reflexo, segundo o fisiologista russo, caracteriza-se por um conjunto de reacções motoras e secretoras a um estímulo natural. Parece óbvio que, para Pavlov, o reflexo é uma característica de todo o organismo animal, a partir de um certo nível de desenvolvimento do sistema nervoso. Ora, no caso de Hegel, estamos na presença de uma categoria ontológica universal que, na sua estrutura formal, se aplica a todo tipo de seres, incluindo os inanimados.

Crítico e a Crise da Ideologia Burguesa, pp. 29-30.

12 Ibidem, p. 33.

${ }_{13}$ Ludwig Landgrebe, „Prinzipien der Lehre von Empfinden“, in Der Weg der Phänomenologie, Güthersloh, Gerd Mohn, 1963, pp. 111-123, pp. 119-121. 
É certo que Magalhães-Vilhena afirma ${ }^{14}$ que o reflexo é uma propriedade geral de toda a matéria. Esta ideia não a consigo encontrar em Pavlov, o que, por si só, não tem, como é óbvio, qualquer problema, mas como Magalhães-Vilhena defende que existem duas classes de matéria qualitativamente distintas ${ }^{15}$, seria interessante que nos tivesse também explicado como se processa o reflexo em cada uma delas. Talvez uma explicação seja avançada para uma dessas duas classes - designada, a certa altura, por "matéria altamente organizada" e que suponho corresponder ao cérebro humano -, quando se afirma que ela transforma a energia da excitação no facto do conhecimento ${ }^{16}$. Faltará explicar como é que a reflexão se processa na outra classe de matéria, supondo que existem apenas duas, o que me parece ser a leitura mais provável do texto. Restaria a possibilidade de se dizer que a primeira classe de matéria - a que não possui a organização complexa da matéria constitutiva do cérebro humano - se auto-reflecte por intermédio da segunda. Suspeito até que a posição de Magalhães-Vilhena sobre o assunto não andará muito longe disto, pelo menos se interpretei correctamente as páginas 51 a 57 do seu livro sobre Sérgio. Aliás, pode ler-se: "No sentido estrito, a 'reflexão' do real físico pela consciência é, de certa maneira, ao cabo de contas, uma 'auto-reflexão' da realidade."17 Perante tal afirmação, tenho apenas de confessar, honestamente, que não consigo entender o que tal coisa possa significar.

Mas tentemos ver um pouco melhor, pois Pavlov distingue ainda, como é do conhecimento geral, o reflexo incondicionado do reflexo condicionado. Este último caracteriza-se por reacções motoras e secretoras provocadas por um estímulo que se substitui ao estímulo natural, após um processo de associação dos dois estímulos ${ }^{18}$. Continua Pavlov que a sua teoria do reflexo repousa sobre três princípios fundamentais: 1) princípio do determinismo, ou seja, há uma causa para todo o efeito dado; 2) princípio da análise e da síntese, ou seja, da divisão de um todo nas suas partes e da sua reconstituição progressiva a partir dos elementos que o constituem; 3) princípio da estruturação, ou seja, da disposição das actividades de uma força no espaço ${ }^{19}$.

\footnotetext{
${ }^{14}$ Vasco de Magalhães-Vilhena, António Sérgio, o Idealismo Crítico e a Crise da Ideologia Burguesa, p. 51.

15 Ibidem, p. 67.

16 Ibidem, p. 51.

${ }^{17}$ Ibidem, p. 51.

${ }^{18}$ I. Pavlov, Typologie et Pathologie de l'Activité Nerveuse Supérieure, Paris: PUF, 1955, pp. 1-2.

19 Ibidem, p. 86.
} 
No processo do pensamento teórico, diz agora Magalhães-Vilhena, a análise e a síntese têm uma base fisiológica na actividade analítico-sintética dos dois hemisférios cerebrais; esta actividade estende-se dos processos mais elementares de sinalização até aos mais complexos, entre os quais encontramos a linguagem, que é a base fisiológica do pensamento, ou, como também é dito ${ }^{20}$, o seu invólucro material, ao mesmo tempo instrumento de fixação e de comunicação. Não irei discutir se todas estas expressões significam ou não o mesmo. Todavia, no que se refere à actividade analítico-sintética dos dois hemisférios, creio que a Magalhães-Vilhena escapou um aspecto importante do pensamento de Pavlov, que não privilegia a actividade analítico-sintética, mas sim a coloca a par da actividade oposta, mas complementar, de estruturação. (Pelo menos se estou a seguir bem o capítulo X da obra de Pavlov intitulada Tipologia e Patologia da Actividade Nervosa Superior.) De facto, podendo a análise e a síntese realizar-se a vários níveis - como o comprovam diversas experiência com cães, privados ou dos lobos occipitais ou dos temporais - é a estrutura do córtex que explica a dispersão dos locais onde elas têm lugar ${ }^{21}$.

\section{A percepção}

As investigações de Pavlov puseram ao nosso dispor um conjunto de informações valiosas, que os progressos recentes das neurociências não tornaram inúteis. Mas o que interessa aqui discutir é o uso que Magalhães-Vilhena faz dos resultados de tais investigações para explicar a natureza da sensação. Esta, na medida em que não constitui apenas a recepção de um estímulo proveniente de um objecto, mas antes se integra numa relação vivida com o real, não interessa directamente ao fisiologista; o que este diz poderá explicar a base fisiológica daquela relação, mas de pouco servirá para entendermos o seu sentido. Excepto, como é óbvio, se quisermos identificar a consciência sensação com a própria sensação, transformando a sensação em algo que ninguém, na realidade, jamais experimentou. Para se evitar estas confusões - em meu entender, pelo menos, são confusões - é que em fenomenologia se pratica a chamada "redução

\footnotetext{
20 Vasco de Magalhães-Vilhena, António Sérgio, o Idealismo Crítico e a Crise da Ideologia Burguesa, p. 34.

21 I. Pavlov, op. cit., p. 90.
} 
fenomenológica". Voltarei a ela um pouco mais abaixo.

Quase há um século, a psicologia gestaltista nascente encontrava razões para pôr em causa a hipótese, que estava na base da psicologia sensualista, segundo a qual existe uma relação fixa entre o estímulo proveniente do objecto e a quantidade objectiva de excitação. Abandonar a hipótese de constância significa reconhecer que o que é dado na percepção - os seus elementos constituintes, os seus aspectos, as suas características - deve ser descrito e analisado tal como se apresenta, sem qualquer referência a uma realidade extrínseca à própria percepção. Isto significa que só podemos dar conta das coisas reais na base do modo como são visadas e do modo como a cada visada corresponde uma forma específica de apresentação ${ }^{22}$.

Avanço, então, a minha tese para interpretar o pensamento de Magalhães-Vilhena sobre este assunto: se o que acontece na consciência dos homens é apenas uma reprodução - Abbildung é o substantivo alemão que encontramos em Engels, por exemplo - dos processos materiais que ocorrem na natureza, torna-se difícil entender como se constitui a unidade da experiência sem a qual a própria ideia de natureza - correlato da ideia de um conhecimento objectivo - não poderia surgir. Reconheço que o problema da unidade da experiência não é uma questão relevante para Magalhães-Vilhena: a "matéria altamente organizada" de que mais atrás falei e que supus corresponder ao cérebro humano adquiriu a possibilidade de reproduzir (abbilden é o verbo alemão) as outras formas menos organizadas, eventualmente no decurso da evolução da espécie e da selecção dos processos adaptativos mais eficazes para a sua sobrevivência. E reparem que não digo que não possa ter sido assim, ou seja, que a explicação para a existência de capacidades específicas do cérebro não deva ser procurada na evolução da espécie. Para mim, o problema encontra-se noutro lado. Mas o mais grave, em meu entender, está no facto de esta Abbildung ser vista como relação entre a natureza humana concreta e a natureza tal como é interpretada pelas ciências da natureza, ou seja, supondo-se que a unidade da experiência se encontra já constituída de acordo com certos pressupostos. (Aquela atitude a que Husserl chama "ingénua", no livro da Crise.)

Isto acarretou já que a experiência sensível fosse vista apenas na sua relação com a estimulação física, de acordo com uma noção de experiência interpretada já em termos psicofisiológicos, em vez ser vista a partir do que se pode constatar numa análise descritiva dos fenómenos perceptivos ${ }^{23}$. Além disso, se podemos admitir que, para cada objecto

22 Aron Gurwitsch, Théorie du Champ de la Conscience (trad. de Michel Butor), Paris: Desclée de Brouwer, 1957, p. 141.

23 Ibidem, p. 80. 
sensível, a constituição da sua identidade se realiza de forma relativamente independente da actividade do Eu (assim, por exemplo, um conjunto de sons de altura ou intensidade variável organiza-se em melodia sem a minha intervenção activa); já no que diz respeito à constituição de objectividades de nível superior (conceitos e categorias, nomeadamente), tal intervenção é obrigatória ${ }^{24}$.

Ernst Mach notara já que, se chamarmos A, B, C... aos complexos de qualidades sensíveis a que chamamos corpos, e K, L, M... ao complexo a que chamamos o nosso corpo, teremos de concluir, na base de experiências simples, que A, B, C... estão sempre determinados por K, L, M...; uma figura cúbica parecerá diferente conforme a vejamos apenas com o olho direito ou apenas com o olho esquerdo. E, como é óbvio, se cerrarmos os dois olhos, não a veremos ${ }^{25}$.

A operação a que Mach procede - que está na origem do que vulgarmente se chama o seu fenomenismo - tem largas semelhanças com a redução fenomenológica, tal como Husserl a entende. O ponto de partida de ambos consiste numa descrição dos dados sensoriais e das suas conexões intrínsecas, abstração feita de qualquer referência ao ser real e às relações de causalidade nele vigentes. É claro que se pode eliminar este procedimento reconduzindo os momentos estruturais específicos da vida da consciência e do seu fluxo temporal ao conjunto de operações que têm lugar no sistema nervoso, um tipo especial de matéria onde, como diria Magalhães-Vilhena, se reflecte um outro tipo qualitativamente diferente de matéria ${ }^{26}$, a que poderíamos chamar "realidade exterior". Ora, esta noção de reflexo (ou de reflexão, se se quiser) parece-me a mim muitíssimo problemática. A "energia de excitação" que Magalhães-Vilhena menciona ${ }^{27}$ - como já mais do que uma vez referi - é algo que nunca ninguém na realidade sentiu, os seus elementos constituintes não são elementos de nenhuma espécie de experiência vivida, mas sim o resultado de uma construção teorética, provavelmente útil para certos fins da ciência ${ }^{28}$, mas, em todo caso, baseada num pressuposto: o de que existe uma dependência exclusiva dos dados sensoriais relativamente aos estímulos físicos ${ }^{29}$ e que

24 Edmund Husserl Erfahrung und Urteil, § 63, Hamburg: Felix Mainer, 1999, p. 301.

25 Ernst Mach, Die Analyse der Empfindungen, trad. cast., Análisis de las Sensaciones, Madrid: Daniel Jorro, 1925, p. 9.

26 Vasco de Magalhães-Vilhena, António Sérgio, o Idealismo Crítico e a Crise da Ideologia Burguesa, p. 67.

27 Ibidem, p. 51.

28 Ludwig Landgrebe, "Prinzipien der Lehre von Empfinden”, p. 115.

29 Aron Gurwitsch, Théorie du Champ de la Conscience, p. 81. 
nesta dependência a sensibilidade realiza a sua função de proporcionar um primeiro e imediato contacto com a realidade.

Tudo o que disse não significa que me encontra mais próximo de Sérgio do que de Magalhães-Vilhena. Efectivamente, creio que nem um nem outro explicam de uma forma satisfatória o modo como as actividades superiores da consciência, explicitamente orientadas por um interesse de conhecimento, se articulam com as actividades de nível inferior, nas quais a consciência apenas sabe de si na base de uma disposição sobre a actividade cinestésica do corpo somático. E, nesta perspectiva, diria até que Magalhães-Vilhena tem razão ao afirmar que o pensamento de Mach é incompatível com a teoria do reflexo. Ao invés, se queremos falar de elementos, estruturas, reflexos ou realizações da consciência deveremos ater-nos, exclusivamente, ao que são os momentos reais da vida da consciência e do seu fluxo temporal, esses momentos em que ela é efectivamente consciência de alguma coisa, ou seja, relação intencional com os seus objectos. 


\title{
RESUMO
}

Este ensaio propõe-se analisar algumas teses de Vasco de Magalhães-Vilhena a propósito do problema do conhecimento, nomeadamente, a doutrina chamado do "reflexo". O ponto de partida é a crítica que o autor dirige a António Sérgio, cuja posição filosófica caracteriza, acertadamente, como idealismo de inspiração neo-kantiana. Magalhães-Vilhena aproxima a doutrina do reflexo, inspirada nas investigações do fisiologista russo I. Pavlov, da noção de reflexão proposta por Hegel na Segunda Parte da Ciência da Lógica. Neste ensaio, contesta-se a legitimidade de tal aproximação. Por fim, em confronto com as posições gnosiológicas de Magalhães-Vilhena (cujo corolário é a dependência dos dados sensoriais relativamente aos estímulos físicos), propõe-se uma análise do fenómeno do conhecimento que tem por base o princípio da análise intencional defendido por Edmund Husserl.

Palavras-chave: idealismo - doutrina do reflexo - reflexão - intencionalidade.

\begin{abstract}
This paper aims to analyze some theses of Vasco de Magalhães-Vilhena regarding the problem of knowledge, namely, the so-called theory of the "reflex". The point of departure is the critic the author addresses to António Sérgio, whose philosophical position is correctly characterized as Neo-kantian Idealism. Magalhães-Vilhena aims to link the doctrine of the reflex, inspired by the research of the Russian physiologist I. Pavlov, to the concept of reflection proposed by Hegel in the Second Part of the Science of Logic. In this paper I question the legitimacy of this connection. At last, confronting the standpoint of Magalhães-Vilhena regarding gnosiological issues (whose corollary is the dependence of sense-data from physical stimuli) I propose an analysis of the phenomenon of knowledge based in the principles of intentional analysis endorsed by Edmund Husserl.
\end{abstract}

Key-words: Idealism - doctrine of the reflex - reflection - intentionality. 